\title{
A FIELD METHOD \\ FOR DETERMINATION OF THE PERFORMANCE PARAMETERS \\ OF AN OPERATING STRUCTURE AND ITS HEATING SYSTEM
}

\author{
A.L. BERLAD
}

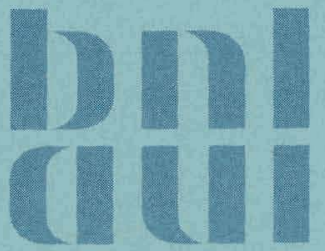

June 1977

\section{DEPARTMENT OF APPLIED SCIENCE}

BROOKHAVEN NATIONAL LABORATORY

ASSOCIATED UNIVERSITIES, INC.

UNDER CONTRACT NO. EY-76-C-02-0016 WITH THE

UNITED STATES ENERGY RESEARCH AND DEVELOPMENT ADMINISTRATION 


\section{DISCLAIMER}

This report was prepared as an account of work sponsored by an agency of the United States Government. Neither the United States Government nor any agency Thereof, nor any of their employees, makes any warranty, express or implied, or assumes any legal liability or responsibility for the accuracy, completeness, or usefulness of any information, apparatus, product, or process disclosed, or represents that its use would not infringe privately owned rights. Reference herein to any specific commercial product, process, or service by trade name, trademark, manufacturer, or otherwise does not necessarily constitute or imply its endorsement, recommendation, or favoring by the United States Government or any agency thereof. The views and opinions of authors expressed herein do not necessarily state or reflect those of the United States Government or any agency thereof. 


\section{DISCLAIMER}

Portions of this document may be illegible in electronic image products. Images are produced from the best available original document. 
BNL 50684

(Energy Conservation-Buildings

and Community Systems - TID-4500)

\title{
A FIELD METHOD \\ FOR DETERMINATION OF THE PERFORMANCE PARAMETERS OF AN OPERATING STRUCTURE AND ITS HEATING SYSTEM
}

\author{
A.L. BERLAD*
}

June 1977

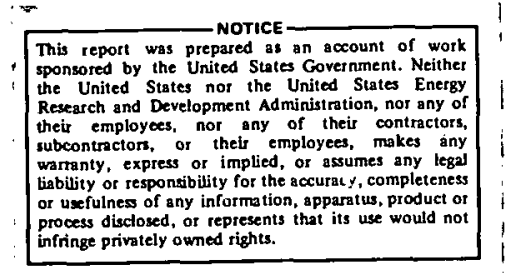

Portions of this research were carried out under the auspices of the United States Energy Research and Development Administration

*College of Engineering and Applied Sciences, State University of New York, Stony Brook, N.Y. 11794

DEPARTMENT OF APPLIED SCIENCE

BROOKHAVEN NATIONAL LABORATORY UPTON, NEW YORK 11973 
NOT I C E

This report was prepared as an account of work sponsored by the United States Government. Neither the United States nor the United States. F.nergy Research and Development Administration, nor any of their employees, nor any of their contractors,

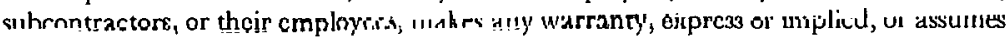
any legal liability or responsibility for the accuracy, completeness or usefulness of any information, apparatus, product or process disclosed, or rcpresents that its use would not infringe privately owned rights.

Printed in the United States of America Available from

National Technical Information Service

U.S. Department of Commerce

5285 Port Royal Road

Springfield, VA 22161

Pricc: Printed Cupy $\$ 3$ Microfiche $\$ 3.00$

August. 1977

8.50 copies




\section{PREFACE}

During the January to May 1977 period, the field methods discussed in this report were employed by the author as the basis for an undergraduate engineering laboratory field experiment at the State University of New York at Stony Brook. Easy implementation of these methods characterized this initial field study. 


\section{CONTENTS}

\section{Page}

I INTRODUCTION AND BACKGROUND................. I

II IN SITU SEASONAL PERFORMANCE--ANALYTIC BACKGOUND....... 5

iti a field method of Determining $\mathscr{L}_{\mathrm{d}},\left(n_{\mathrm{c}}\right)$ vS. $\left(\dot{\mathrm{m}}_{\mathrm{f}} / \dot{\mathrm{m}}_{\mathrm{f}, \mathrm{d}}\right)$, AND $(n)$ FOR A RESIDENTIAL HOME............... 8

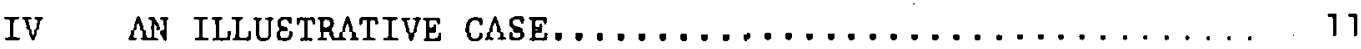

V DISCUSSION OF ILLUSTRATIVE CASE TREATED IN SECTION IV... 15

VI DISCUSSION OF FIELD METHOD.................. 17

VII EVALUATION OF SOLAR LOADING AND OTHER HEAT SOURCE/SINK EFFECTS................... 20

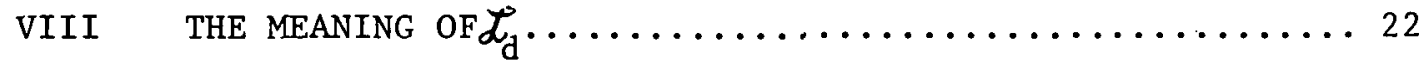

IX SEASONAL PERFORMANCE AND HEATING COSTS FOR A SPECIFIC

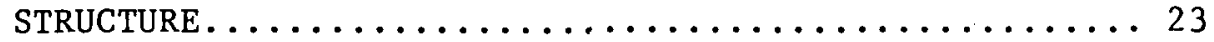

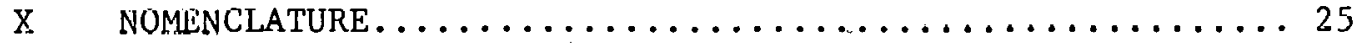

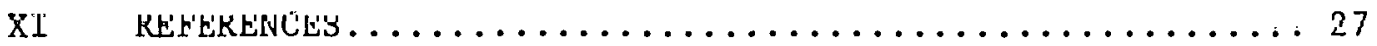

XII TABLES AND FIGURES $\ldots \ldots \ldots \ldots \ldots \ldots \ldots \ldots \ldots \ldots \ldots \ldots$ 


\section{(I) INTRODUCTION AND BACKGROUND}

It is widely recognized (e.g. 1, 2, 3, ...) that substantial national energy and cost savings are possible, through the upgrading of the energy performance of our inventory of homes, and their heating systems. For the individual homeowner, optimum approaches to achievement of these savings are less well defined. For the individual, a quantitative understanding of the detailed performance of the specific home and the specific heating system is necessary.

There appears to exist substantial, detailed information on the energy consumption history (electrical, oil, and/or natural gas usage) for the individual homes in our national inventory. The files of energy suppliers and/or utilities are the chief repositories of these records. However, even if one were to extract all information implicit in these detailed records alone, it is not possible to assess adequately the potential for improvement--either for any given home or, correspondingly, for the national inventory of homes. To make such an assessment one should characterize quantitatively all of the following: (4)

(a) the intrinsic merits of the in situ heating system

(b) the in situ heating load required by the house, as a function of weather, climate, and existing operating modes

(c) the seasonal performance of the in situ coupled systems, house, heating system, and the operational space conditioning strategies.

It is not difficult to illustrate the above. Consider, for example, the case of a typical single family residence for the 
Metropolitan New York area. We may take it to have some $1500 \mathrm{ft}^{2}$ of floor space on a single level and to consume 1500 gallons of number 2 fuel oil per year. To what extent may this annual fuel usage be ascribed to

(a) an average quality house (as regards its design heat load) heated by an average heating system (as regards tits sceady state and cycle efficiencies), installed and operated in a typical way (as regards installation and operational mode),

(b) a superior house (very well insulated, relatively. free of infiltration losses) heated by an inferior heating system (low steady state and cycle efficiencies),

(c) an infertor house (very poorly insulated, sustaining substantial infiltration losses) heated by a superfor heating system (outstanding steady state and cycle efficiencies ${ }^{4}$ ),

(d) a potentially superior house and potentially superior heating system; the former requiring easily installed insulation and inflltration oupprcosion, the latter requiring the replacement of a faulty, overfired fuel injection system,

(e) etc., etc.?

The following information is needed to acecss the ovcrall system, for purposes of rational upgrading and cost-benefit evaluation: 
(1) The in situ design heating load of the house.

(2). The in situ steady state and cycle efficiencies of the heating system.

Given these data, quantitative measures of performance may then be deduced and employed quantitatively to confirm the bases for the use of the recorded 1500 gallons of fuel oil. Of course, it is of little interest to simply confirm what we already know. It is of substantial interest, however, to use the BNL Seasonal Performance Formulation ${ }^{(4)}$ to calculate the energy and cost savings to be derived from a specific upgrading of the heating system, the house, and the operational mode.

In essence, one cannot quantitatively assess energy and cost savings derivable from possible improvements until after the in situ performance of each of the subsystems (house and heating system) has been quantitatively characterized. Having accomplished such a task, we can then calculate the seasonal heating costs to be expected ${ }^{(4)}$ from upgrading of each of the following: the house, the heating system, their modes of coupling and operation. Having achieved both the in situ quantitative characterization of the home systems and the operating cost and energy savings accessible with existing technology (upgrading) one may then quantitatively assess the worthiness (payback period, etc.) of proposed improvements.

It is an unfortunate fact that today's homeowner is not aware of the in situ performance of his home or his heating system. It is even more distressing to realize that currently available field inspection methods do not generally provide the quantitative information 
needed for such an assessment of a home's performance. This report is concerned with field and analytic methods that may be employed to provide the needed data--the in situ design heat load of a house and the in situ steady state and cycle efficiency curve for the coupled, fossil-fuel fired heating system. 
(II) IN SITU SEASONAL PERFORMANCE--ANALYTIC BACKGOUND

Previous analyses ${ }^{(4)}$ of the seasonal performance of fossilfuel-fired heating systems have emphasized deduction of the seasonal fuel usage rate to be expected for a given system--heating system serving a specific house in a specific climate during a specific hour-by-hour weather history, subject to a specific operating strategy. In this work, the formulation previously employed ${ }^{(4)}$ is shown to be useful in quantitatively estimating the in situ contributions of "heating system" and "house" to the "seasonal performance"--the total seasonal usage of fuel for space heating. A Conservation Equation presented in reference (4) is shown below.

$$
\dot{\mathrm{m}}_{\mathrm{f}} \eta_{\mathrm{c}} \eta_{\mathrm{s}} \Delta_{c}+\sum_{\mu} \mathrm{s}_{\mu}=\mathrm{L}+\mathrm{H}_{0}, \quad \text { for } \mathrm{T}_{\mathrm{c}}<\mathrm{T}^{*}
$$

Symbol definitions appear in a nomenclature section. A full discussion of the bases for equation (1) is given in reference (4). In equation (1) the hourly load, L, does not include a11 the source and sink terms that may be other than linear functions of the dimensionless temperature difference, $\tau$. These terms appear in the summation, $\sum \mathrm{S}_{\mu}$, and may include such diverse sources as the heating output of kitchen appliances, electric lighting, solar inputs, the energy output of living occupants, etc.. $\sum \mathrm{S}_{\mu}$ may also include such diverse sinks as venting of conditioned air by unwisely installed boilers or furnaces, by externally vented clothes dryers, bathroom and kitchen vents, etc..

Equation (1) implies that the hourly heating and domestic hot water loads may be adequately met by a boiler/furnace whose 
fractional ON TIME is less than unity. (2-4) Accordingly, it is generally found that

$$
\dot{\mathrm{m}}_{\mathrm{f}} \eta_{\mathrm{c}} \eta_{\mathrm{s}} \Delta_{\mathrm{c}}+\sum_{\mu} \mathrm{s}_{\mu}>\mathrm{L}+\mathrm{H}_{0}
$$

as the fractional ON TIME goes to unity, and $\eta_{c}$ goes to unity. That is, the heating system is generally overfired. Thus, for steady state operation of the heating system, equation (1) becomes

$$
\dot{\mathrm{m}}_{\mathrm{f}, \mathrm{d}} \mathrm{n}_{\mathrm{s}} \Delta_{c}+\sum_{\mu} \mathrm{s}_{\mu}=\left(\mathrm{L}+\mathrm{H}_{0}\right) \alpha
$$

For a properly and wisely installed heating system, (4) subjected to no extraneous sources and sinks, equations (1) and (2) become:

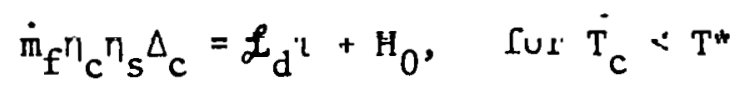

and

$$
\dot{\mathrm{m}}_{\mathrm{f}, \mathrm{d}} \mathrm{n}_{\mathrm{s}} \Delta_{\mathrm{c}}=\left(\mathcal{E}_{\mathrm{d}}+\mathrm{H}_{0}\right) \alpha
$$

A realistic example for which equations (3) and (4) are appropriate may be worth noting. Consider a winter nighttime period (say 11:00 p.ill. - 6:00 a.ll.) for a single family residence for which combustion and stack-venting boiler/furnace air is ducted from the exterior (nonconditioned air). There are trivial light sources. No cooking occurs. There is no solar loading. Infiltration losses are not induced by the operation of various venting devices. Residents are asleep. Indeed, for such a case, one may generally take $\mathrm{H}_{0}=0$. A realistic example for which the (more general) equations (1) and (2) are needed may also easily be cited. Consider a daytime period (say 10:00 a.m. - 6:00 p.m.) for a single family residence for which an unwisely installed boiler/furnace uses conditioned air for its 
stack-venting and for combustion. Many electrical appliances may be operating. Substantial solar loading (at windows and elsewhere) may obtain. For such a case, equations (1.) and (2) are more appropriate than (3) and (4) .

For a given residence under given operating conditions, the relations among $\eta_{s}, \eta_{c}, \dot{m}_{f}, \dot{m}_{f, d}, \Delta_{c}, L, \tau, H_{0}, \alpha, s_{\mu}$ are fixed. A sufficiently detailed experimental assessment of the values of some of these parameters, taken with equations (1) and (2) (or with equations (3) and (4), where conditions permit) may be used to determine the remaining unknowns. Given a residence for which $\mathcal{L}_{d}$ and $\eta_{c}$ vs. $\left(\dot{\mathrm{m}}_{f} / \dot{\mathrm{m}}_{f, d}\right)$ are unknown, one may seek a set of characteristic heating system and other measurements in order to determine the unknowns. After such determination is made, a seasonal operating cost (performance) may be calculated. (4) Most importantly, once such determination is made, seasonal operating costs for an improved (modified) house and/or heating system may be calculated. Thus, one may then more rationally assess the cost-effectiveness of proposed home (and/or heating system) modifications in terms of the quantitative change in anticipated seasonal operating costs.

The next section examines a method of employing the previously discussed formulation to the in situ determination of $\mathcal{L}_{d}$ and $\eta_{c} v s$. $\left(\dot{\mathrm{m}}_{\mathrm{f}} / \dot{\mathrm{m}}_{\mathrm{f}, \mathrm{d}}\right)$. 
(III) A FIELD METHOD OF DETERMINING $\mathscr{L}_{\mathrm{d}},\left(\eta_{\mathrm{C}}\right)$ VS. $\left(\dot{\mathrm{m}}_{\mathrm{f}} / \frac{\dot{\mathrm{m}}}{\mathrm{f}}, \mathrm{d}_{\mathrm{d}}\right)$, AND $(\alpha)$ FOR A RES IDENTIAL HOME

Assume that a study is made of a fossil-fuel-heated house during the (nighttime) hours when extraneous solar and electrical heat loading are trivially $\operatorname{smal1}$ (e.g., 11:00 p.m. - 6:00 a.m.) and where all values of $\sum \mathrm{S}_{\mu}$ may be taken to be zero. For the case of an unwise installation (e.g., infiltration of outside air induced by furnace/ boiler installation in a conditfoned space) not a11 $\varepsilon_{\mu}$ values may be taken to be zero. Such cases will be discussed subsequently.

For $H_{0}=0$, we have a corresponding value of $\alpha=\alpha_{0}$. Equations (1) and (2) become:

$$
\dot{\mathrm{m}}_{\mathrm{f}} n_{\mathrm{c}} n_{\mathrm{s}} \Delta_{c}=\mathrm{L}=\mathscr{L}_{\mathrm{d}}\left(\frac{\mathrm{T}^{*}-\mathrm{T}_{c}}{\mathrm{~T}^{*}-\mathrm{T}_{\mathrm{d}}}\right)
$$

and

$$
\dot{\mathrm{m}}_{\mathrm{f}, \mathrm{d}} n_{\mathrm{s}} \Delta_{\mathrm{c}}=\dot{\mathcal{H}}_{\mathrm{d}^{\alpha}}{ }_{n}
$$

Assume that we proceed, as follows, in the field:

(1) Adjust the heating system:

C.1ean the boiler, as necessary, and reduce the firing. rate where a cursory estimate indicates inordinately large overfiring. Assure that stack smoke is minimal.

(2) Provide for a series of measurements to be made of

(a) the characteristic indoor temperature, 'l' $*$

(b) the characteristic outdoor temperature, $\mathrm{T}_{\mathrm{c}}$

(c) the (hourly) fractional ON TIME of the furnace/boiler, $\left(\dot{\mathrm{m}}_{\mathrm{f}} / \dot{\mathrm{m}}_{\mathrm{f}, \mathrm{d}}\right)$

It is possible to have these measurements made and recorded 
automatically.

(3) Record the steady state firing rate, $\dot{\mathrm{m}}_{\mathrm{f}, \mathrm{d}}$.

(4) Measure.(1) the steady-state efficiency of the heating

system, $\eta_{s}$.

Over a period of time, data are recorded which provide:

$\mathrm{T}^{*}$ and $\mathrm{T}_{\mathrm{c}, \mathrm{i}}$ vs. time and $\left(\dot{\mathrm{m}}_{\mathrm{f}} / \dot{\mathrm{m}}_{\mathrm{f}, \mathrm{d}}\right)$ vs. time.

We may analyze the data in the following way. First, find the largest value of $\left(\dot{\mathrm{m}}_{\mathrm{f}} / \dot{\mathrm{m}}_{\mathrm{f}, \mathrm{d}}\right)_{i}$ recorded. This should correspond to the lowest value ${ }^{(4)}$ of $T_{c, i}$, for average wind conditions. Meteorological data provide both $\mathrm{T}_{\mathrm{c}, \mathrm{i}}$ and wind conditions. Examination of data for both exceptional and poor boilers ${ }^{(4)}$ indicates that (within $5 \%$ ) we may approximate $\eta_{c}$ by:

$$
\eta_{c}^{0}=0.12\left(\dot{m}_{f} / \dot{m}_{f, d}\right)+0.88
$$

for the range

$$
0.40 \lesssim\left(\dot{\mathrm{m}}_{\mathrm{f}} / \dot{\mathrm{m}}_{\mathrm{f}, \mathrm{d}}\right) \leq 1.0
$$

Assuming that a minimally adequate job of reducing firing rate was achieved at the inception of the field study, it is reasonable to expect that the largest observed value(s) of $\left(\dot{m}_{f} / \dot{m}_{f, d}\right)$ will lie within this range. Thus, we may use equation (5) to estimate the design heat load, $\varkappa_{d}$. An uncertainty of $(5 \%)$ in $\left(\eta_{c}\right)$ corresponds to an uncertainty of only (5\%) in $\mathscr{L}_{\mathrm{d}}$. Take this estimate of $\mathcal{L}_{\mathrm{d}}$ to be $\mathcal{L}_{\mathrm{d}, 1}$. Equation (6) may then be used to obtain a corresponding estimate of $\alpha_{0}$. Take this estimate to $\alpha_{0,1}$. Thus, the three parameters

$$
\begin{aligned}
& \cdot \eta_{c, i}^{\circ} \text { corresponding to }\left(\dot{m}_{f, i} / \dot{m}_{f, d}\right) \text { and } T_{c, i} \\
& \cdot \alpha_{0,1} \text { corresponding to } \mathcal{E}_{d, 1} \\
& \cdot \mathscr{E}_{d, 1} \text { corresponding to } n_{c, i}^{0}
\end{aligned}
$$


satisfy equations (5), (6) and (7). Dividing (5) by (6) gives:

$$
\left(\frac{\dot{\mathrm{m}}_{\mathrm{f}, \mathrm{i}}}{\dot{\mathrm{m}}_{\mathrm{f}, \mathrm{d}}}\right) \eta_{\mathrm{c}, \mathrm{i}}=\left(\frac{1}{\alpha_{0,1}}\right)\left(\frac{\mathrm{T}^{*}-\mathrm{T}_{\mathrm{c}, \mathrm{i}}}{\mathrm{T}^{*}-\mathrm{T}_{\mathrm{d}}}\right)
$$

where $\mathrm{T}^{*}, \mathrm{~T}_{\mathrm{d}}, \alpha_{0,1}, \dot{\mathrm{m}} \mathrm{f}, \mathrm{d}$ and $\mathscr{L}_{\mathrm{d}, 1}$ are known constants. Field measurements yield $\left(\dot{\mathrm{m}}_{\mathrm{f}, i} / \dot{\mathrm{m}}_{\mathrm{f}, \mathrm{d}}\right)$ as a function of $\left(\mathrm{T}^{*}-\mathrm{T} \mathrm{c}, \dot{i}\right)$. Thus, for a given $\left(T^{*}-T_{c, i}\right)$ value, equation (8) may be used to determine the corresponding cycle efficiency, $n_{c, i}$.

It follows that a series of $\left(\dot{\mathrm{m}}_{\mathrm{f}, i} / \dot{\mathrm{m}}_{\mathrm{f}, \mathrm{d}}\right)$ vs. $\left(\mathrm{T}^{*}-\mathrm{T} c, i\right)$ observations may be employed [with equation (8)] to generate the curve defined by

$$
\left(n_{c, i}^{0}\right) \text { vs. }\left(\dot{m}_{f, i} / \dot{m}_{f, d}\right)
$$

Where the mean deviation of the data used to generate such a least squares curve can be significantly improved by a $\pm 5 \%$ change in the value of $\mathscr{L}_{\mathrm{d}, 1}$ it should be done. Only modest iteration is to be expected, in view of the very small uncertainty in $L_{d}$ implicit in $\mathscr{C}_{\mathrm{d}, 1}($ on $1 \mathrm{y} 5 \%)$

Thus the "best fit" of observational data to yield a suitable $\left(n_{c}\right)$ vs. fractional "ON TIME" curve simultaneously yields a "best fit" for $\left(\alpha_{0}\right)$ and $\mathscr{Z}_{\mathrm{d}}$.

To then find the overfiring ratio, $(\alpha)$ which corresponds to a given nonzero use of domestic hot water, $\mathrm{H}_{0}$, we employ the relation [from (4) and (6)]:

$$
\alpha=\left(\frac{a_{0}}{1+\left(\frac{\mathrm{H}_{0}}{\mathrm{~L}_{\mathrm{d}}}\right)}\right)
$$




\section{AN ILLUSTRATIVE CASE}

Assume that we have: complete information about a residence and its heating system. In the absence of solar loading, for all $s_{\mu}=0$, we have (for a clean, tuned, in-the-field, oil-fired boiler):

$$
\begin{aligned}
& \mathfrak{L}_{\mathrm{d}}=50,000 \mathrm{BTUH} \\
& \rho_{\mathrm{oil}}=7.128 \mathrm{lbs} / \mathrm{gallon} \\
& \dot{\mathrm{m}}_{\mathrm{f}, \mathrm{d}}=8.554 \mathrm{lbs} / \mathrm{hr} \text { (corresponds to } 1.2 \mathrm{gph} \text { ) } \\
& \mathrm{n}_{\mathrm{s}}=0.70 \\
& \mathrm{~T}^{*}=68^{\circ} \mathrm{F} \\
& \mathrm{T}_{\mathrm{d}}=3^{\circ} \mathrm{F} \\
& \mathrm{H}_{0}=7,500 \mathrm{BTUH} \\
& \Delta_{\mathrm{c}}=19,500 \mathrm{BTU} \text { per } 1 \mathrm{~b} \\
& \alpha \quad=(1.692)(1.2)=2.030
\end{aligned}
$$

Laboratory determined values of $\left(n_{c}\right)$ vs. $\left(\dot{\mathrm{m}}_{\mathrm{f}} / \dot{\mathrm{m}}_{\mathrm{f}, \mathrm{d}}\right)$ are shown in Table (1), as assumed for this case. The corresponding $T_{c, i}$ values derive from the heating system-load coupling. $(4,5)$ we now assume that previously described diagnostic approach (to the determination of unknowns). is to be employed by an in-the-field investigator.

The above noted (true) values of $\dot{\alpha}_{d}, \alpha$, and the $\eta_{c}$ vs. $\left(\dot{\mathrm{m}}_{\mathrm{f}} / \dot{\mathrm{m}}_{\mathrm{f}, \mathrm{d}}\right)$ curve are not known to the in-the-field investigator. Assuming that the investigator finds rather smoke-free operation of the field unit, the existing $1.2 \mathrm{gph}$ nozzle is simply replaced by a fresh one of the same rating. The value of $n_{s}$ is then readily determined by stack gas testing. (1) Thermophysical properties are available from standard tabulation (e.g., ref. 5). 
Over a period of time, the in-the-field investigator records

$$
\begin{array}{r}
T^{*} \text { vs. time } \\
T_{c, i} \text { vs. time } \\
\left(\dot{\mathrm{m}}_{f, i} / \dot{\mathrm{m}}_{f, d}\right) \text { vs. time }
\end{array}
$$

the characteristic value of $\left(\mathrm{m}_{f, i} / \mathrm{m}_{f, d}\right)$ for any value of $T_{c, i}$ is determined as the cumulative value taken over a number of cycles over which $T_{c, i}$ has remained essentially constant. The period of time of the investigation may span several days (or even weeks). The el emental simplicity of the data to-be-gathered suggests that automatic recording (and subsequent automatic analysis) of these data can be achieved ${ }^{(6)}$ easily.

Once the data are gathered, we may set aside (for other studies of importance) those that pertain to solar influences, nontypical wind conditions, and $\mathrm{S}_{\mu}$ and $\mathrm{H}_{0}$ values that are nontrivially nonzern. Redundant data at any given $\left(\mathrm{T}_{\mathrm{c}, i}\right)$ may be averaged and equation (7) employed to estimate $\eta_{c, i}^{0}$ for the largest value of $\left(m_{f, i} / m_{f, d}\right)$ observed. Assume that this value is

$$
\left(m_{f, i} / m_{f, d}\right)=0.45 .
$$

This is a conservative assumption, inasmuch as the larger the maximum observed value of $\left(m_{f, i} / m_{f, d}\right)$, the more accurate the initial estimate of the value of $\mathcal{L}_{\text {. }}$. Equation (5) implies that the temperature, $T_{c, i}$, observed to correspond to $\left(\mathrm{m}_{\mathrm{f}, \mathrm{i}} / \mathrm{m}_{\mathrm{f}, \mathrm{d}}\right)=0.45$ is given by:

$$
\begin{aligned}
T_{c, i} & =T^{*}-\left(\frac{m_{f, i} n_{c}{ }^{n} \Delta_{c}}{Z_{d}}\right)\left(T^{*}-T_{d}\right) \\
& =68-\left(\frac{(0.45)(8.554)(0.89)(0.70)(19,500)}{50,000}\right)(65)
\end{aligned}
$$

and

$$
\mathrm{T}_{\mathrm{c}, \mathrm{i}}=7.2^{\circ} \mathrm{F}
$$


Given these observations, then, equation (7). may be used to obtain a close estimate for the cycle efficiency at $\left(\dot{\mathrm{m}}_{\mathrm{f}} / \dot{\mathrm{m}}_{\mathrm{f}, \mathrm{d}}\right)=0.45$. Equation (7) gives

$$
n_{c}^{0}=0.934
$$

That is, our initial estimate of $\left(n_{c}\right)$ corresponding to $\left(\dot{m}_{f} / \dot{m}_{f, d}\right)=0.45$ is high by approximately $5 \%$. We may now use the $\eta_{c}^{0}$ value so obtained (along with the corresponding temperatures and fractional ON TIME) with equations (5) and (6) to obtain initial estimates of $\alpha$ and $\mathscr{L}_{\mathrm{d}}$. These are, from (5):

or

$$
\mathscr{L}_{d}^{0}=\left(\dot{m}_{f^{n}} n_{c}^{0} n_{s} \Delta_{c}\right)\left(\frac{T^{*}-T_{d}}{T^{*}-T_{c, i}}\right)
$$

$$
\begin{aligned}
& \mathscr{L}_{\mathrm{d}}^{0}=(0.45)(8.554)(0.934)(0.7)(19,500)(65.0) /(60.8) \\
& \mathscr{L}_{\mathrm{d}, 1}=\mathscr{L}_{\mathrm{d}}^{0}=52,465 \text { BTUH. }
\end{aligned}
$$

from (6):

$$
\begin{aligned}
\alpha_{0,1} & =\frac{\dot{m}_{f, d} n_{s} \Delta_{c}}{L_{d, 1}} \\
& =\frac{(8.554)(0.70)(19,500)}{52,465} \\
\alpha_{0,1} & =2.226
\end{aligned}
$$

The set of data, and first estimates, available to the field investigators is now

$$
\begin{aligned}
& \mathcal{L}_{\mathrm{d}}^{0}=\mathcal{L}_{\mathrm{d}, 1}=52,465 \\
& \alpha_{0,1}=2.226 \\
& n_{s}=0.70 \\
& \left.\begin{array}{l}
\eta_{c}^{0}=0.934 \\
\left(\dot{\mathrm{m}}_{\mathrm{f}} / \dot{\mathrm{m}}_{\mathrm{f}, \mathrm{d}}\right)=0.45
\end{array}\right\} \text { for } \mathrm{T}_{\mathrm{c}, \mathrm{i}}=7.2^{\circ} \mathrm{F}
\end{aligned}
$$


The necessary correspondence of predicted and observed pairs of values of $\left(\dot{\mathrm{m}}_{\mathrm{f}, \mathrm{i}} / \dot{\mathrm{m}}_{\mathrm{f}, \mathrm{d}}\right)$ vs. $\left(\mathrm{T}_{\mathrm{c}, \mathrm{i}}\right)$ has been noted previously. (4) Accordingly, the pairs of corresponding values shown in Table 1, for $\left(\dot{\mathrm{m}}_{\mathrm{f}} / \dot{\mathrm{m}}_{\mathrm{f}, \mathrm{d}}\right)$ vs. $\mathrm{T}_{\mathrm{c}}$ are those that are expected to be observed, even though the corresponding $n_{c}$ values are a priori unknown to the field investigators.

Given this estimate of $\mathcal{L}_{d}^{0}$ and the value of $\eta_{c, i}^{0}=0.934$ for $\mathrm{T}_{\mathrm{c}, \mathrm{i}}=7.2^{\circ} \mathrm{F}$, we may now generate an estimated set of $\left(\eta_{c}^{0}\right)$ vs. $\left(\dot{\mathrm{m}}_{\mathrm{f}} / \dot{\mathrm{m}}_{\mathrm{f}, \mathrm{d}}\right)$ values, employing

(a) equation (5) for the regime $\left(\dot{m}_{f} / \dot{m}_{f, d}\right) \leq 0.45$, and

(b) equation (7) for the regime $0.45 \leq\left(\dot{\mathrm{m}}_{\mathrm{f}} / \dot{\mathrm{m}}_{\mathrm{f}, \mathrm{d}}\right) \leq 1.00$ Sets of values of $\left(\eta_{c}^{0}\right)$ vs. $\left(\dot{\mathrm{m}}_{f} / \dot{\mathrm{m}}_{\mathrm{f}, \mathrm{d}}\right)$ and $\left(\eta_{c}^{0}\right)$ vs. $\left(\mathrm{T}_{c}\right)$ are given in Table 2. Comparison with the "true" $\left(n_{c}\right)$ values (also given in Table 2) shows the closeness of the correspondence. Figure (1) compares the $n_{c}^{0}$ and $\eta_{c}$ curves. It appears unnecessary to seek higher order approximations for the cycle efficiency curve.

We may also use equation (9) to estimate $\alpha^{0}$, the overfiring ratio corresponding to an assumed value of $\mathrm{H}_{0}=7500 \mathrm{BTUH}$. Employing $\alpha_{0,1}=2.226$ and $\mathcal{L}_{\mathrm{d}}^{0}=52,465$ BTUH, equation (9) yields

$$
\begin{aligned}
& \alpha^{0}=\left(\frac{\alpha_{0}, 1}{1+\left(\frac{H_{0}}{L_{\dot{d}}^{n}}\right)}\right), \text { or } \\
& \alpha^{0}=1.948 .
\end{aligned}
$$

A comparison of actual and (measured or) estimated values of important parameters is given in Tables (2) and (3) as well as in Figure (2) . 
V. DISCUSSION OF ILLUSTRATIVE CASE TREATED IN SECTION IV.

The illustrative case considered in Section IV has been carefully selected. It corresponds to a (hypothetical) cycle efficiency curve which is substantially inferior to any yet found in BNL's testing program. Accordingly, the equation (7) estimates for fractional oN TIMES (greater than or equal to 0.45 ) are in greater error than can be expected to be encountered in the field, for virtually any really inferior boiler installation. Yet, the deduced estimate of cycle efficiency (on this range of fractional ON TIMES) lies within some five percent of the actual values (Table 2). Further, application of the analytic formulation to the remainder of the fractional ON TIME range provides deduced cycle efficiency estimates which

(a) coincide with the correct values for $\left(\dot{\mathrm{m}}_{\mathrm{f}} / \dot{\mathrm{m}}_{\mathrm{f}, \mathrm{d}}\right)=0.03,1$

(b) lie within $5 \%$ of the correct values over the entire range $0 \leq\left(\dot{\mathrm{m}}_{\mathrm{f}} / \dot{\mathrm{m}}_{\mathrm{f}, \mathrm{d}}\right) \leq 1$.

This agreement is shown in Table (2) and illustrated in Figure (2). For efficient boiler systems, the actual cycle efficiency vs. fractional ON TIME curves ${ }^{(4)}$ are expected to be substantially superior to that predicted by equation (7), in the neighborhood of $\left(\dot{\mathrm{m}}_{\mathrm{f}} / \dot{\mathrm{m}}_{\mathrm{f}, \mathrm{d}}\right)=0.45$. Nevertheless, the resulting underestimate derived from equation (7) will again be in error by no more than some $5 \%$. As before the "standby condition" fractional ON TIME $\left(n_{c}=0\right.$ where the fractional ON TIME is nonzero) is a measureable quantity. By definition $\eta_{c}=$ unity for a fractional ON TIME of unity. Accordingly, the formulation is (again) capable of generating a cycle efficiency 
curve which

(a) coincides with the correct values for $\left(\dot{\mathrm{m}}_{\mathrm{f}} / \dot{\mathrm{m}}_{\mathrm{f}, \mathrm{d}}\right)$ equal to unity and at the "standby condition".

(b) lies within $5 \%$ of the correct values over the entire range $0 \leq\left(\dot{\mathrm{m}}_{\mathrm{f}} / \dot{\mathrm{m}}_{\mathrm{f}, \mathrm{d}}\right) \leq 1$

Clearly, then, the formulation is capable of generating estimated values of $\mathcal{L}_{\mathrm{d}}, \alpha$, and $\eta_{\mathrm{c}}$ vs, $\left(\dot{m}_{\mathrm{f}} / \dot{\mathrm{m}}_{\mathrm{f}, \mathrm{d}}\right)$ which are accurate to five percent, given that fractional ON TIME data of 0.45 (or greater) are observed. This is true for both the best and the worst possible cycle efficiency curves that may be expected. The accuracy of estimates for intermediate cases will be even better. 


\section{DISCUSSION OF FIELD METHOD}

The review of the illustrative case treated (Sections IV and V) shows that an in-the-field inspection and analysis of an a priori unknown house (and its heating system) is expected to yield $\mathcal{L}_{\mathrm{d}}, \alpha, \eta_{\mathrm{s}}$, and $n_{c}$ vs. $\left(m_{f} / m_{f, d}\right)$. All these values are expected to be accurate to $5 \%$ or better, including the cycle efficiency curve. It is a simple matter to show that correspondingly accurate seasonal performance (for the specific house and its heating system) is easily deducible by the methods of reference 4 .

More significantly, specific upgrading of the house's thermal properties (reduction of $\mathcal{L}_{\mathrm{d}}$ ) as well as an upgrading of the heating system (increases in $\eta_{s}$, decreases in $\alpha$, complete change of boiler to one having better steady state and cycle efficiencies, etc.) results in quantitatively calculable increases in Seasonal Performance And Costs (reference 4). Thus, the power and utility of this in-thefield method derives from the facts that

(a) it accurately provides quantitative data on the efficiency parameters of the heating system, the heat load characteristics of the house, and the appropriateness of the sizing of the heating system,

(b) the parameters so determined are sufficient to permit an accurate seasonal performance calculation for the in situ system-house and heating system, subject to the sizing and operating constraints that apply,

(c) improvements in house or heating system may be quantitatively characterized in terms of changes in heat load $\left(\mathcal{L}_{d}\right)$, sizing $(\alpha)$, steady state efficiency $\left({ }_{s}\right)$, cycle effictency and operating strategy 
$\left[n_{c}\right.$ vs. $\left.\left(\dot{\mathrm{m}}_{\mathrm{f}} / \dot{\mathrm{m}}_{\mathrm{f}, \mathrm{d}}\right)\right]$. Quantitative changes in these (now determined) parameters permit quantitative determination of the changes in seasonal performance and seasonal costs,

(d) both the increase in seasonal performance and the decrease in seasonal costs which derive from a proposed heating system and/or house upgrading can be quantitatively assessed. Accordingly, the estimated seasonal savings can be quantitatively calculated. It is clear that without the ability to calculate both seasonal costs for an in situ system and for its proposed modification, that a quantitative verification of predicted seasonal savings is not possible,

(e) the fleld measurements required for the deductions previously described are simple enough to permit automatic recording equipment, coupled with the formulation described herein, to yield the results of interest. That is, one can utilize a set of automatic recording of sensor readouts (in conjunction with this formulation and well known computational methods) to generate the (a) - (d) information cited above. This is the basis of a Brookhaven National Laboratory Field Method and Apparatus for In Situ Determination of Heating System Overall Efficiency, Structure Design Heat Load and Seasonal Performance and cooto. (6)

(f) Without a detailcd "diagnostic assay" for each slfuclure in the national inventory, no quantitative local, regional or national "diagnostic assay" is achievable. Obviously, the seasonal operating costs for any community of homes is nothing more than the sum of the operating costs of individual homes. Although costs for a home, or a community of homes, may be known without the "diagnostic assay" 
described herein, the quantitative calculation of cost. savings of proposed system's modifications require a "diagnostic assay".

It has been assumed, in the foregoing, that the system under in situ study is properly and wisely installed. This is not always the case. Methods of estimating induced infiltration losses (7) indicate that the use of conditioned air for combustion and for stack vent dilution can decrease the apparent efficiency of a heating system by some three to four percent. The estimates employed in references (7) and (8) may be employed to adjust the seasonal efficiency of such an improperly installed system.

It has also been assumed, in the foregoing, that the system under in situ study is not subject to solar loading or significant internal heat sources/sinks. For purposes of these analysis, this is assured by selecting only night-time data under conditions when residents are normally asleep. Nevertheless, automatic recording of data [part (e)] can provide valuable information on system characteristics during periods of solar loading and internal heat generation. One may assess the influence of solar and other loading in a number of ways--each of which requires the use of the more general energy conservation equation (with sources and sinks) given as equation (1). This is discussed next. 
VII. EVALUATION OF SOLAR LOADING AND OTHER HEAT SOURCE/SINK EFFECTS

In the previously discussed "diagnostic assay" only selected observational data were employed--those for which $\left(\mathrm{S}_{\mu}\right)$ were considered negligible. Implicit. in the system data for which non-negligible $\mathrm{S}_{\mu}-$ values apply, are the informational sources that are subsequently applicable to a determination of the integrated inputs associated with SOLAR and other sources/sinks.

Consider, then, that the previously discussed "diagnostic assay" has been completed (on the basis of selected observations) and that an evaluation of solar and other heat source/sink effects is sought. In order to do this, we first consider an integrated form of equation (1). We integrate equation (1) over any desired time period that is at least as long as the characteristic time period for the effect of interest. Where solar loading is of interest this could be a time period of the order of a day to one as long as the entire heating 'season:

Integration of equation (1) over a time period (test period) of interest yields

$$
\int_{t_{1}}^{t_{2}} \sum_{\mu} s_{\mu} d t=\sum_{i} f_{d}\left(\frac{T^{*}-T_{c}, i}{l^{*}-l_{d}}\right) A_{1}-\sum_{i} m_{L}, i n_{c, i} n_{s} \Delta_{L} \theta_{i}
$$

where $t_{1}=$ time at the beginning of test period; $t_{2}=$ time at the end of the test period; $\sum_{i} \theta_{i}=\left(t_{2}-t_{1}\right)=$ total number of hours in the test period; $\theta_{i}=$ number of hours in the test period for which $\mathrm{T}_{\mathrm{c}}=\mathrm{T}_{\mathrm{c}, \mathrm{i}}$.

We note that each of the two summations on the RHS of equation (10) 
is easily calculable, once the previously discussed "diagnostic assay" is completed. Thus, for example, if we take $\sum_{i} \theta_{i}=24$ hours, then we can determine the LHS of equation (10) for a 24 -hour period of interest. Of course, this implies that we now employ all the data recorded (not just the late night data) over the 24 -hour period of interest. Thus, determination of the RHS of equation (10) for the specific 24-hour period of interest yields the total solar (and other, as appropriate) contribution to the heating of the conditioned space for the time period of interest.

It is important to note that the solar loading (and discharging) of insolated buildings can involve a number of large time lags. In general, for moderate-sized, frame structures, a 24-hour period is long enough to accommodate this phenomenon.

It is also apparent that we can evaluate the seasonal contribution of solar (and other) loadings to the in situ performance of a given building. Thus, if we have complete, seasonal (hour-by-hour) data for any building, we can obviously set $\sum_{1} \theta_{i}=5832$ hours, where these 5832 hours correspond to the October 1 through May 31 time period (heating season). Accordingly, the total enthalpy gained by the conditioned space (via solar and other nonheating system loading) is determined by calculating the RHS of equation (10), integrated over the heating season period.

These in situ studies and their results, promise to give information that has not been heretofore available. 
VIII. THE MEANING OF $\mathscr{L}_{\mathrm{d}}$ -

As a design concept, easily calculated ${ }^{(5)}$ and utilized by architects and space conditioning specialists, the steady state design heat load, $\mathcal{L}_{d}$, is well defined. The in situ, effective value of $\mathcal{L}_{d}$ is generally not adequately determinable from such a calculation. Variations in construction practice, topography, exposure to sun and weather, landscaping, evolutionary changes in house properties, occupant practices, heating system design and operating practices, etc. all influence the in situ value of $\boldsymbol{l}_{\mathrm{d}}$. In a strict sense, the normal heating operation of a structure is at best only quasi-steady (rather than steady) in that the cyclic (2) heating of the conditioned space must introduce unsteady behavior to the heat loss rate. Accordingly, the in situ value of $\mathcal{L}_{\mathrm{d}}$ may differ substantially from a best estimate made at a time when the structure was in the design stage.

One important strength of the method discussed in this report derives from its reliance on data obtained while the structure, its heating system, and its control philosophy all operate in their normal manner. The observed, in situ value of $\mathcal{L}_{\mathrm{d}}$ is the one normally experienced by the structure, under normal cyclic heating ${ }^{(2)}$ and cooling. 
IX. SEASONAL PERFORMANCE AND HEATING COSTS FOR A SPECIFIC STRUCTURE

Given the performance information (for heating system and structure) derived from a field study of the kind discussed herein, one can easily employ previously discussed methods of analysis (4) to deduce seasonal costs for the given structure, served by the given heating system, subject to the detailed weather pattern for the geographical area of interest. The seasonal costs for any given case may already be very well known, of course. The precise mass of fuel used during the heating season may be a matter of accurate record. Nevertheless, the new information derived from this in-the-field "diagnostic assay" permits one to quantitatively calculate ${ }^{(4)}$ the expected changes in seasonal costs

(a) given a set of proposed changes to the heating system

(b) given a set of proposed changes to $\mathcal{L}_{\mathrm{d}}$ (new insulation, etc.) In essence, a study of this kind is necessary in order to establish quantitatively the expected benefits to be derived from proposed specific heating system and/or home heat loss upgrading.

The seasonal value of

$$
\int_{t_{1}}^{t_{2}} \sum s_{\mu} d t
$$

is a parameter of utmost interest. This value is derivable by the methods of reference (4) taken together with the methods discussed herein. The seasonal non-fossil-fuel heat source is simply given by the calculated values obtained from equation (10), where $\sum \theta_{i}=5832$ hours, taken over the heating season (October 1 through May 31). By 
grouping the solar contribution with other (internally generated) heating sources, we maintain the functional simplicity of $\mathscr{X}_{\mathrm{d}}$, as utilized here. Accordingly, the fraction of the seasonal heat load provided by solar and other nonheating-system sources is given by

$$
\begin{aligned}
& \int_{t_{1}}^{t_{2}} \sum_{\mu} s_{\mu} d t
\end{aligned}
$$

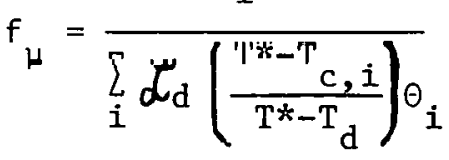

Where "solar energy technology" is proposed for the increase in the value of $f_{\mu}$ of a given system (in-the-field case), it would appear reasonable that the proposer be able to estimate the expected new value of $f_{\mu}$. Rational judgments may then be made of the wisdom of adding new technology. It is interesting to note [equation (10)] that as $\mathrm{f}_{\mu}$ is made larger, for a given system, that the seasonal. efficiency of an (unmodified) fossil fuel heating system may be expected to decrease (averaged fractional ON TIME decreases). 


\section{$X$. NOMENCLATURE}

$\mathrm{C}_{\mathrm{e}} \quad$ - hourly operating costs of the electrical components of a fossil-fuel-fired space heating (and domestic hot water) system (dollars/hour).

$\mathrm{C}_{\mathrm{m}} \quad$ - specific fossil fuel costs (dollars per pound of fuel).

$C_{t} \quad$ - annual energy costs for the system (dollars per year).

$\mathrm{H}_{0} \quad$ - domestic hot water load (BTU/Hr).

L - heat loss (load) for conditioned space of a characteristic structure (BTU/Hr.).

$f_{\mu} \quad$ - fraction of seasonal heat load provided by solar and other non-heating-system sources

$\mathcal{L}_{\mathrm{d}}$ - design heat loss (load) for conditioned space of a characteristic structure (BTU/Hr).

$\dot{\mathrm{m}}_{\mathrm{f}} \quad$ - mass flow rate of fuel, actual $(1 \mathrm{bs} / \mathrm{hr})$.

$\dot{\mathrm{m}}_{f, d} \quad$ - mass flow rate of fuel, design (lbs/hr).

$\dot{m}_{f}^{*}$

- mass flow rate of fuel during the nonheating season, actual (lbs/hr).

M - total mass of fuel used during the year (1bs).

$M_{1} \quad$ - total mass of fuel used during the heating season (lbs).

$M_{2} \quad$ - total mass of fuel used during the nonheating season (1bs).

$M_{1 p} \quad$ - total mass of fuel that would be used during the heating season by a (perfect) system for which all $n$ values are unity (lbs.)

$M_{2 p} \quad$ - total mass of fuel that would be used during the nonheating season by a (perfect) system for which all $n$ values are unity (1bs).

$\mathrm{n}_{\mathrm{i}} \quad$ - number of hours in the year, having a characteristic outdoor temperature, $T_{c, i}$, during the heating season $\left(T_{c, i}<T^{*}\right)$.

$n^{*} \quad-$ total number of hours in the nonheating season $\left(T_{c} \geq T^{*}\right)$.

$\mathrm{S}_{\mu} \quad$ - heat source or sink, of the $\mu^{\text {th }}$ kind, in the conditioned space $(B T U / H r)$. 


$$
\begin{aligned}
& t_{1} \quad-\text { time at the beginning of the test period } \\
& t_{2} \quad-\text { time at the end of the test period } \\
& \left(t_{2}-t_{1}\right)-\text { equals } \sum_{i} \theta_{i} \\
& \mathrm{~T} \quad-\text { temperature }\left({ }^{\circ} \mathrm{F}\right) \\
& \mathrm{T}_{\mathrm{C}} \quad \text { - characteristic outside temperature }\left(^{\circ} \mathrm{F}\right) \\
& \mathrm{T}_{\mathrm{c}, \mathrm{i}} \text { - characteristic outside temperature of the ith value }\left({ }^{\circ} \mathrm{F}\right) \\
& \mathrm{T}_{\mathrm{d}} \quad \text { - outside temperature used for the design heat loss calculations } \\
& \text { for the conditioned space }(\cap F) \text {. } \\
& T^{*} \quad \text { - temperature of the conditioned space }\left({ }^{\circ} \mathrm{F}\right) \\
& \alpha \quad \text { - the overfiring ratio } \\
& \Delta_{c} \quad \text { - heat of combustion of fuel (BTU/1b) } \\
& \theta_{i} \quad \text { - number of hours in the test period for which } T_{c}=T_{c, i} \\
& \bar{\eta} \quad \text { - overall efficiency of the boiler/furnace } \\
& \bar{n}^{*} \quad \text { - overall efficiency during the nonheating season } \\
& \eta_{c}^{*} \quad-\text { cycle efficiency } \\
& \bar{n}_{i} \text {. - cycle efficiency during the nonheating season } \\
& \eta_{s} \quad \text { overall efficiency when the outside characteristic temperature } \\
& \text { has a value } T_{c, i} \\
& \text { - dimensionless temperature difference for the conditioned space, } \\
& {\left[\left(\mathrm{T}^{*}-\mathrm{T}_{\mathrm{C}}\right) /\left(\mathrm{T}^{*}-\mathrm{T}_{\mathrm{d}}\right)\right]} \\
& \phi \quad \text { - an experimentally determined function that related the cycle } \\
& \text { efficiency to the actual (and design) tiring raess of a buller/ } \\
& \text { furnace, for a given characteristic cycle. } \\
& w_{H} \quad \text { - heating season clcctrical puwtr luyulrements for fosail-fucl- } \\
& \text { fired system during ON mode } \\
& \omega_{S} \quad \text { - summer season electrical power requirements for fossil-fuel- } \\
& \text { fired system during ON mode }
\end{aligned}
$$


(XI) REFERENCES

1. Berlad, A. L., Batey, J. J. Urban Analysis 1, 95 (1972).

2. Berlad, A. L., Salzano, F. J., Batey, J. ENERGY 1, 429 (1976).

3. Hise, E. C. Oak Ridge National Laboratory Report ORNL-NSF-EP-82.

4. Berlad, A. L., Lin, H. C., Batey, J., Salzano, F. J., Yu, W.S., Hoppe, R., Allen, T. Seasonal Performance and Energy Costs of 0il or Gas-Fired Boilers and Furnaces, BNL $\overline{5064} \overline{7 \text {, March } 1977 .}$

5. ASHRAE: Handbook of Fundamentals.

6. Berlad, A. L., Salzano, F. J., Hoppe, R., Batey, J. BNL Patent Disclosure.

7. Bonne, U., Johnson, A. E. 'Thermal Efficiency in Non-Modulating Combustion Systems," Proceedings, Purdue University Conference, October 1974 .

8. Bonne; U., Johnson, A. E., Glatzel, J., Torberg, R. Analysis of New England Oil Burner Data, Final Report on Contract NBS-514736 by Honeywe11 Corporate Research Center (August 29, 1975).

9. Berlad, A. L. In Situ Evaluation of Solar Effects on Space Conditioning Costs, (in preparation) 
Table 1

The Given $\left(n_{c}\right)$ vs. $\left(\dot{m}_{f} / \dot{m}_{f}, d\right)$ Values for the Boiler Considered in the Illustrative Example of Section IV.

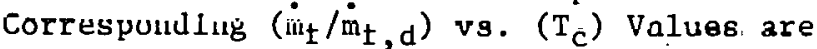
Prescribed by Equation (5).

\begin{tabular}{rrr}
$T_{\mathrm{C}}{ }^{\circ} \mathrm{F}$ & $\left(\dot{\mathrm{m}}_{\mathrm{f}} / \dot{\mathrm{m}}_{\mathrm{f}, \mathrm{d}}\right)$ & $\eta_{\mathrm{c}}$ \\
\hline-83.8 & 1.00 & 1.00 \\
-16.8 & 0.60 & 0.92 \\
-0.3 & 0.50 & 0.90 \\
7.2 & $0.4 b$ & 0.89 \\
14.6 & 0.40 & 0.88 \\
32.3 & 0.28 & 0.84 \\
44.9 & 0.20 & 0.76 \\
53.8 & 0.14 & 0.67 \\
57.1 & 0.12 & 0.60 \\
Standby & 0.030 & 0.000
\end{tabular}


Table 2

Estimated vs. Actual Values of Cycle Efficiency, for the Illustrative Example of Section IV.

\begin{tabular}{|c|c|c|c|c|}
\hline & \multirow[b]{3}{*}{$\mathrm{T}_{\mathrm{c}},{ }^{\circ} \mathrm{F}$} & \multirow[b]{3}{*}{$\left(\dot{\mathrm{m}}_{\mathrm{f}} / \dot{\mathrm{m}}_{\mathrm{f}, \mathrm{d}}\right)$} & \multicolumn{2}{|c|}{$n$} \\
\hline & & & Estimated & Actual \\
\hline & & & $n_{c}^{0}$ & $n_{c}$ \\
\hline \multirow{3}{*}{$\begin{array}{c}\text { Not } \\
\text { Observed }\end{array}$} & -83.8 & 1.00 & 1.000 & 1.000 \\
\hline & -16.8 & 0.60 & 0.952 & 0.92 \\
\hline & -0.3 & 0.50 & 0.940 & 0.90 \\
\hline \multirow{7}{*}{ Observed } & 7.2 & 0.45 & 0.934 & 0.89 \\
\hline & 14.6 & 0.40 & 0.923 & 0.88 \\
\hline & 32.3 & 0.28 & 0.881 & 0.84 \\
\hline & 44.9 & 0.20 & 0.798 & 0.76 \\
\hline & 53.8 . & 0.14 & 0.701 & 0.67 \\
\hline & 57.1 & 0.12 & 0.628 & 0.60 \\
\hline & Standby & 0.030 & 0.0000 & 0.00 \\
\hline
\end{tabular}


Table 3

A Comparison of Prescribed and (Measured or) Deduced Estimates of Values of Important Parameters for the Illuslralive Example of scction. IV.

\begin{tabular}{|c|c|c|}
\hline Parameter & $\begin{array}{l}\text { Prescribed } \\
. \quad \text { Value }\end{array}$ & $\begin{array}{c}\text { (Measured or) } \\
\text { Deduced Estimate }\end{array}$ \\
\hline Design Heat Load & $50,000$. BTUH & 52,465 BTUH \\
\hline Overfiring Ratio & 2.030 & 1.948 \\
\hline$\eta_{s}:$ & 0.70 & 0.70 \\
\hline$\eta_{c}$ vs. $\left(\dot{m}_{f} / \dot{m}_{f, d}\right)$ & $\begin{array}{l}\text { Tables } 1 \text { \& } 2 \\
\text { Figures } 1 \text { \& } 2\end{array}$ & $\begin{array}{l}\text { Table } 2 \\
\text { Figure } 2\end{array}$ \\
\hline$\dot{\mathrm{m}}_{\mathrm{f}, \mathrm{d}}$ & $8.554 \mathrm{lb} / \mathrm{hr}$. & $8.554 \mathrm{lb} / \mathrm{hr}$. \\
\hline
\end{tabular}




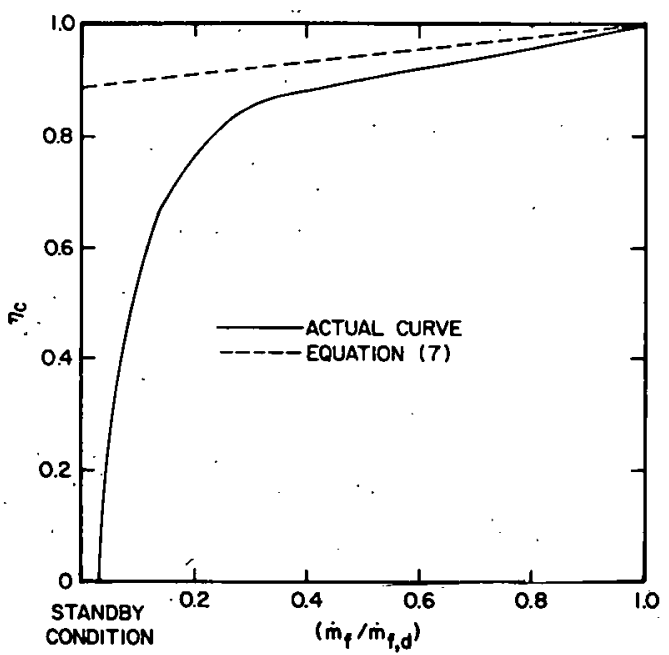

Figure 1. The given cycle efficiency curve for the illustrative case of Section IV.

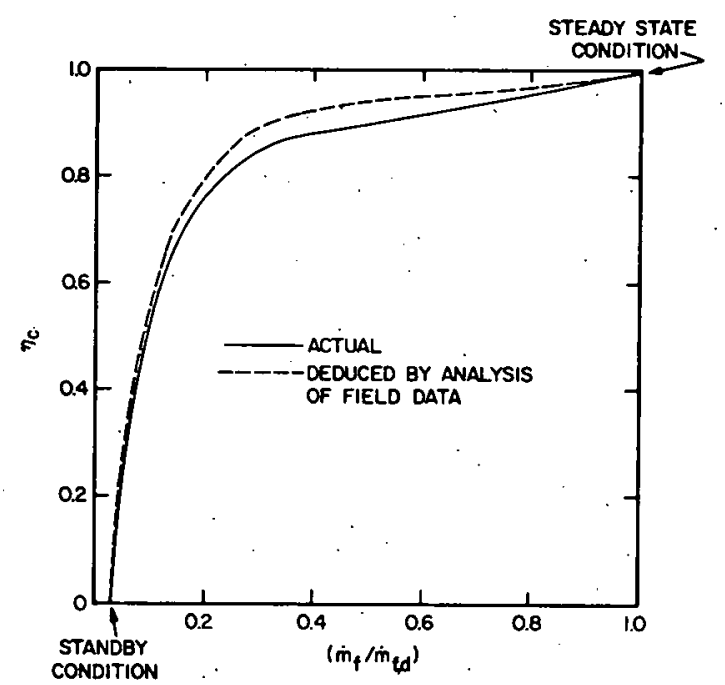

Figure 2. Comparison of the given and analytically deduced cycle efficiency curves for the illustrative case of section IV. 